\title{
Chapter 18 \\ Reaching Latinos Through Social Media and SMS for Smoking Cessation
}

\author{
Patricia Chalela, Alfred L. McAlister, Edgar Muñoz, Cliff Despres, \\ David Akopian, Sahak Kaghyan, Andrea Fernandez, Pramod Sukumaran, \\ and Amelie G. Ramirez
}

\section{Background}

Smoking is the leading cause of premature, preventable death in the country, accounting for about 480,000 deaths per year, including 41,000 from secondhand smoke. This means that one in five deaths per year are due to cigarette smoking. Tobacco's impact on cancer and heart/lung disease is well known [1, 2]. Of all smoking-related premature deaths, about 36\% are due to cancer, $39 \%$ due to heart disease, and $24 \%$ due to lung disease. In general, mortality among smokers is three times higher than that among nonsmokers. On average, smokers die 10 years earlier than nonsmokers and cost billions of dollars to the nation, including $\$ 170$ billion in direct medical care; more than $\$ 156$ billion in lost productivity due to tobaccorelated diseases and disability, of which $\$ 5.6$ billion are due to secondhand smoke exposure [2-4].

In Texas, smoking kills more than 25,000 people per year and 3000 of those are in South Texas [5]. Almost $90 \%$ of adult smokers start smoking by age 18, and almost all (99\%) of daily tobacco users try their first cigarette by age 26 [2]. Smoking prevalence is highest (23.5\%) among US young adults aged 18-29 and even higher among those with less than a high school education (28.7\%) and those living at or below the poverty level $(25.5 \%)$ [1, 2, 6-8]. About $24 \%$ of Latinos aged 18-39 in

P. Chalela $(\bowtie) \cdot$ E. Muñoz $\cdot$ C. Despres $\cdot$ A. Fernandez $\cdot$ P. Sukumaran · A. G. Ramirez

UT Health San Antonio, San Antonio, TX, USA

e-mail: chalela@uthscsa.edu

\author{
A. L. McAlister \\ University of Texas School of Public Health, Austin, TX, USA \\ D. Akopian · S. Kaghyan \\ University of Texas at San Antonio, San Antonio, TX, USA
}


the program areas are current smokers [6]. Among young adult Latinos aged 18-29 in the study areas, smoking rates are similar to those in this age group nationally and the state overall [7]. Smoking rates are low among older Latinos in Texas, and notably higher among young adult Latino men than women.

For young adults, particularly among lower-income Latinos, mobile and social media are increasingly viable communication choices [9-12]. Nine out of ten Latino adults own a smartphone [9] and have a Facebook account, making Facebook the most frequently used social media platform in this group [10, 11]. Latino young adults are heavy users of mobile-only texting, apps, and Internet, and trends in use of mobile-only social media are rapidly rising among lower-income Latinos [11]. Smartphone social media interventions are an innovative, evidence-based, recommended approach for promoting healthy behavior changes among young people [13-18].

Telephone counseling is a well-studied service with strong evidence of effectiveness [19], particularly among younger smokers - among whom rates of cessation are more than doubled by telephone counseling [20-23]. However, telephone counseling services reach only $1-2 \%$ of smokers annually and only $0.9 \%$ of Latinos [24, 25]. Online and mobile applications have also been validated by research indicating similar levels of effect on cessation rates at much lower unit costs [13, 14, 26-28]. Smartphones have the potential to provide personalized smoking cessation support. Research has shown that support delivered via mobile phone text messaging doubled rates of biochemically validated smoking cessation rates at 6 months over controls (10.7\% vs. 4.9\%) [13]. More recent studies, including a Cochrane Review [26], concluded unambiguously that texting interventions can significantly increase odds of successful smoking cessation, with a pooled RR of 1.7, with some studies performing even better [26]. Motivational messages and behavior-change methods in phone or face-to-face smoking cessation support can be modified for delivery via text messaging combined with social media with content tailored to the quitter's gender, ethnicity, and age $[13,27,28]$. Thus, support can be delivered where the person is located without them having to attend services, providing anonymity people like, and it can be interactive, allowing participants to get extra help if needed $[13,27,28]$. Text messaging can also include embedded links to videos and other content to offer peer modeling for cessation behaviors [29]. Its usefulness can be further increased by adding connections to social media and obtaining user profiles to personalize messages to gender and marital and parental status [30]. Young smokers, and particularly lower-income Spanish-speaking young adults for whom mobile devices are a primary point of Internet access, can be effectively served by text messaging cessation program methodology [13, 14, 27-29, 31].

We present results from Quitxt, a text-messaging tobacco cessation program promoted via social media to reach young adult Latinos aged 18-29 in South Texas, a marginalized population with low access to cessation services. 


\section{Methods}

The Quitxt geographic area is South Texas, a 53,000-square-mile area that borders Mexico and contains 4.9 million people. This region includes the Rio Grande Valley, one of the most medically underserved and impoverished areas in the nation, characterized by gaps in public health services, poor access to health care, significant environmental health concerns, and elevated chronic disease rates. About $72 \%$ of young adults in this region are Latino [32]. Of this region's 38 counties, 25 are rural and 21 are Health Professional Shortage Areas. The region's population is more than $30 \%$ uninsured, younger and less educated than the state average, and experiences high poverty rates $(23.6 \%)$. About $70 \%$ of residents in this region speak Spanish at home $[32,33]$.

\section{Program Development}

Formative research took place during the first 6 months of the program, including review of existing evidence-based short message service (SMS) cessation services (i.e., smokefree.gov) and focus groups with young adults (English and Spanish) from San Antonio and the South Texas border area, to ensure that the program message library was culturally and linguistically appropriate.

\section{Pretesting}

With input from focus groups, we developed preliminary content and protocols for our intervention and constructed beta versions of all key promotional messages and protocol elements for pretesting. To identify any potential technical issue prior to program launch, we conducted beta testing of the program with young adult smokers who enrolled in the program via Facebook, received texts, and responded to social media and video links embedded in texts.

\section{Process}

To enroll in the program participants must be 18 years of age or older, current smokers, willing to set a quit date within 14 days, and provide baseline data. The program responds to text codes with a sequence of interactive messages beginning with collection of baseline data that includes basic demographics (i.e., age, ethnicity, gender), 
number of cigarettes smoked per day, e-cigarette use, and binge drinking behavior. Participants are then prompted to choose either "quit tomorrow" or set a "quit date" within 2 weeks. Based on the selection, a specific message sequence follows. The program provides motivational messages, tips to manage cravings and difficult situations, and support 24/7. After their quit date, enrollees are also encouraged to text "help" if they are having difficulty avoiding cigarettes; when they text "help," the system texts to ask if the help needed is due to "stress" or "mood," and depending on their text reply, they are then sent either a prompt and link to breathing exercises (for stress) or a message with links to diverting, humorous videos (for mood). When enrollees fail to reply to texted questions at any point in the protocol, the system is designed to repeat the question twice before moving forward with the messaging sequence whether replies are received or not. Texts also include links to mobile webpages with short videos, music, and other fun and helpful content. These pages (Fig. 18.1) correspond to primary elements of the text messaging component: (1) reasons and motivation for quitting; (2) obtaining social support; (3) nicotine replacement therapy; (4) increasing physical activity; (5) breathing exercises for managing stress; (6) things to do instead of smoking; (7) avoiding relapse by talking yourself out of smoking; (8) predicting, planning, and practicing for difficult situations; and (9) avoiding binge drinking (Fig. 18.1). The messaging system was built and operated by the Software Communication and Navigation Systems Laboratory at the University of Texas at San Antonio.
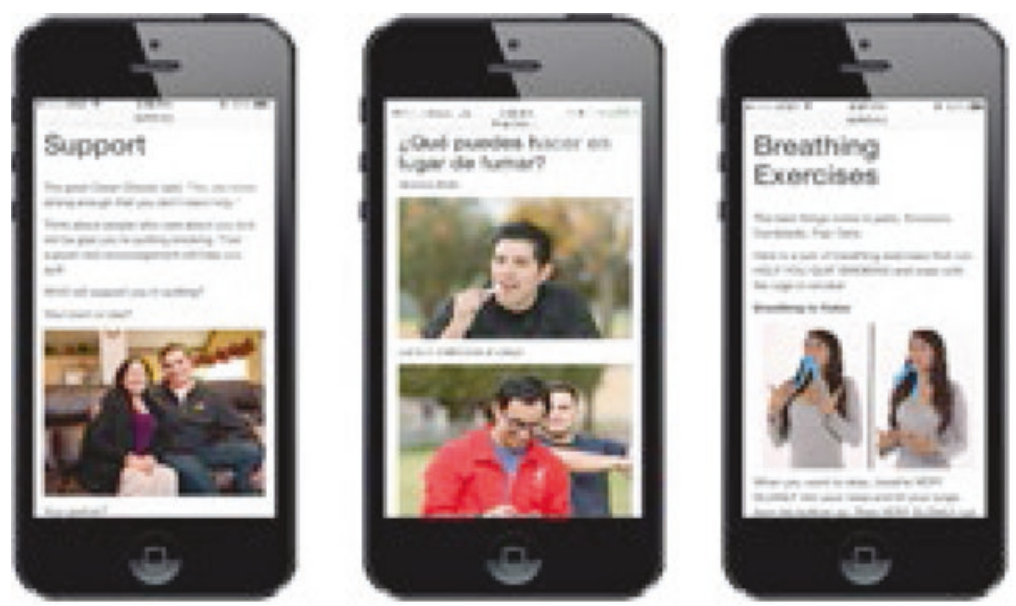

Fig. 18.1 Screenshots of webpages. (Reproduced with permission of Quitxt/Institute for Health Promotion Research, UT Health San Antonio; (c) 2018 Quitxt/Institute for Health Promotion Research, UT Health San Antonio. All rights reserved) 


\section{Program Promotion}

Program enrollment is promoted using mainly social media (i.e., Facebook, Instagram, Twitter), in addition to local mass media publicity and outreach at colleges, universities, trade schools, and other venues attended by young adults. The program uses social media ads with different themes (i.e., disgust, confidence in quitting) and styles (cowboy, metro, punk, graphic novel). Participants are prompted to click on the ad to visit the program homepage for more information or to text a code corresponding to the channel of recruitment (Fig. 18.2).

\section{Results and Discussion}

This was not an experimental trial, and no data were collected to control for use of pharmacological or other behavioral interventions, but we did collect data on enrollment, continuation of service utilization, and self-reported cessation status.
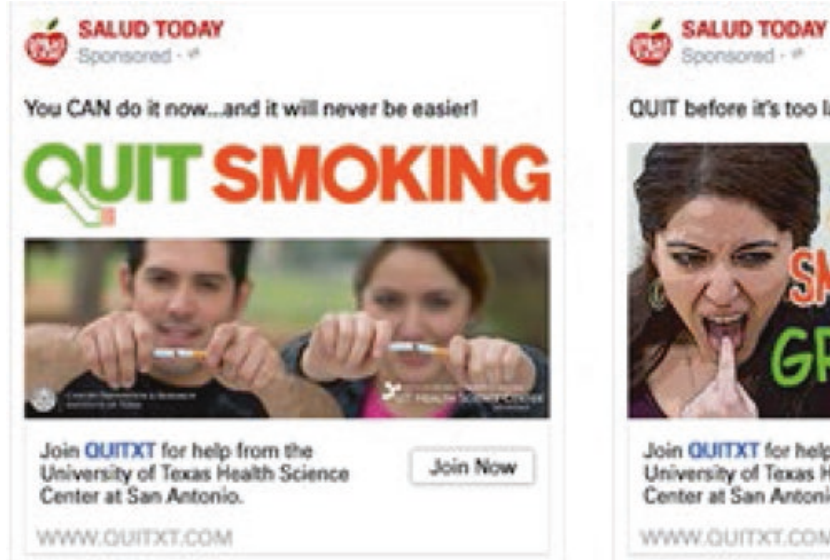

Quir befoce ir's too late 8 live 10 years longerl

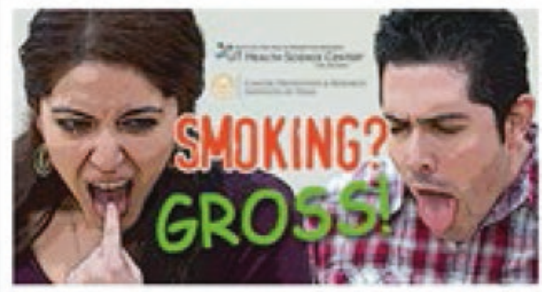

Join QuTXXT fee help from the

University of Texess Health Science Join Now Center at San Anbonio.

www cumrer.com
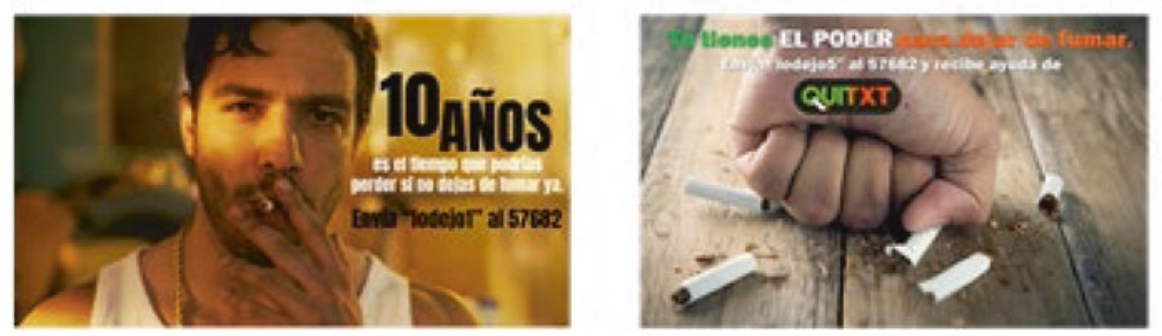

Fig. 18.2 Sample of social media ads. (Reproduced with permission of Quitxt/Institute for Health Promotion Research, UT Health San Antonio; (C) 2018 Quitxt/Institute for Health Pro-motion Research, UT Health San Antonio. All rights reserved) 
Cessation success was assessed with a question texted from the service 222 days (7 months) following the enrollees' selected quit dates that measured 24-h point prevalence abstinence (no smoking in the past day). This measure of cessation yields estimated cessation rates that are highly correlated with abstinence assessed for longer intervals, and the question can be answered more accurately than questions about smoking in the past week or month [34]. If this were a clinical trial, more extensive measures of cessation success would be warranted, but guidelines for research on cessation do not call for biochemical validation of self-reported abstinence in texted or other low-response demand measurement contexts [35].

A total of 798 enrollees are included in the present group assessment. Participants were recruited from October 2015 to January 2016, with 70\% (555) texting in response to Facebook advertising, 14\% (111) responding to publicity, 9\% (70) responding to outreach, and $8 \%$ (62) responding to Twitter or Pandora Internet Radio. Facebook advertising with a theme of confidence and the metro/urban style was the most productive recruitment source and yielded enrollees at a cost of approximately $\$ 120$ each.

Chi-square tests and multivariate analyses were used to determine the statistical significance of differences between program user groups. The mean age of Quitxt participants was 29.3, and 55\% were below the age of 30 (Table 18.1). More men $(57 \%)$ than women $(43 \%)$ enrolled in the program, and $36 \%$ identified themselves as Hispanic or Latino. The mean number of cigarettes smoked per day was 11.5.

Table 18.1 Quitxt participant characteristics and cessation rates

\begin{tabular}{|c|c|c|c|}
\hline Characteristic & Frequency $(\%)$ & Cessation $(\%)$ & OR \\
\hline \multicolumn{4}{|l|}{ Age } \\
\hline$\leq 29$ & $398(55.1)$ & 23.9 & Ref \\
\hline$\geq 30$ & $324(44.9)$ & 23.5 & 0.90 \\
\hline \multicolumn{4}{|l|}{ Gender } \\
\hline Male & $400(56.5)$ & 23.7 & Ref \\
\hline Female & $308(43.5)$ & 24.7 & 1.05 \\
\hline \multicolumn{4}{|l|}{ Ethnicity } \\
\hline Hispanic/Latino & $246(35.5)$ & 25.2 & 1.18 \\
\hline Non-Hispanic/Latino & $446(64.5)$ & 24.4 & Ref \\
\hline \multicolumn{4}{|c|}{ Cigarettes smoked per day } \\
\hline$<10$ cigs/day & $308(46.4)$ & 26.3 & Ref \\
\hline$\geq 10$ cigs $/$ day & $356(53.6)$ & 25.3 & 0.97 \\
\hline \multicolumn{4}{|l|}{ Use of e-Cigs (ever) } \\
\hline Yes & $302(49.6)$ & 19.9 & $0.34 *$ \\
\hline No & $307(50.4)$ & 36.2 & Ref \\
\hline \multicolumn{4}{|l|}{ Binge drinking } \\
\hline Yes & $385(64.1)$ & 23.4 & $0.37 *$ \\
\hline No & $216(35.9)$ & 37.5 & Ref \\
\hline
\end{tabular}

$* p<0.001$ 
Approximately half (302) of the 609 enrollees who replied to the question about e-cigarette use reported that they were using e-cigarettes to help reduce their cigarette smoking. Among the 601 enrollees who texted a reply to the question about alcohol use, 64\% (385) reported binge drinking (4 or more drinks on a single occasion in the past month among women, 5 or more among men).

Regarding cessation rates, $21.4 \%$ of participants (171/798) reported 24-h point prevalence abstinence from smoking 7 months after their selected quit date. There were no significant differences in cessation rates between males and females, younger and older enrollees, or Latino enrollees and others. Participants who reported use of e-cigarettes were less likely to report smoking cessation at 7 months than those who did not report e-cigarette use: $20 \%$ (60/302) versus 36\% (111/307; chi-square test, $p<0.001$ ). Those who reported binge drinking were less likely to report smoking cessation at 7 months than those who did not report binge drinking: $23 \%(90 / 385)$ versus $37 \%(81 / 216$; chi-square test, $p<0.001)$.

Smoking cessation rates reported here are higher than the rates reported in previous studies of mobile cessation services [26], but are consistent with research on telephone counseling for young adults [20]. Measurement of point prevalence of 24-h abstinence yields cessation rate estimates that are slightly higher than longer-reported intervals of abstinence [34]. In addition, enrollees in this service were mostly light to moderate smokers (mean consumption 11.5 cigarettes per day at baseline), which may have contributed to the relatively high cessation rates achieved.

\section{Conclusion}

Texting and mobile media services for smoking cessation can be effectively delivered to young adults in South Texas. Support can be delivered 24/7 wherever the person is located, providing the anonymity people like, and it can be interactive, allowing participants to obtain help when it is most needed. This is a highly scalable service, which makes mobile personalized smoking cessation advice/support an affordable approach to reach disadvantaged population groups, produce a public health impact, reduce health service costs, and reduce smoking-related health disparities.

\section{References}

1. US Department of Health and Human Services. Preventing tobacco use among youth and young adults: a report of the surgeon general. Atlanta: US Department of Health and Human Services, Centers for Disease Control and Prevention, National Center for Chronic Disease Prevention and Health Promotion, Office on Smoking and Health; 2012. http://www.surgeongeneral.gov/library/reports/preventing-youth-tobacco-use/full-report.pdf. Accessed 18 Oct 2018.

2. US Department of Health and Human Services. The health consequences of smoking -50 years of progress. A report of the surgeon general. Atlanta: US Department of Health and 
Human Services, Centers for Disease Control and Prevention, National Center for Chronic Disease Prevention and Health Promotion, Office on Smoking and Health; 2014. http://www. surgeongeneral.gov/library/reports/50-years-of-progress/full-report.pdf. Accessed 18 Oct 2018.

3. National Cancer Institute. Harms of cigarette smoking and health benefits of quitting. 2017. https://www.cancer.gov/about-cancer/causes-prevention/risk/tobacco/cessation-fact-sheet. Accessed 18 Oct 2018.

4. Jha P, Ramasundarahettige C, Landsman V, Rostron B, Thun M, Anderson RN, et al. 21stcentury hazards of smoking and benefits of cessation in the United States. N Engl J Med. 2013;368:341-50.

5. Texas Department of State Health Services. FACT: tobacco use is a tremendous burden to all Texans. 2014. http://www.prc6.org/wordpress/wp-content/uploads/2014/03/FACT-TobaccoUse-is-a-Tremendous-Burden-to-All-Texans.pdf. Accessed 19 Oct 2018.

6. Center for Behavioral Health Statistics and Quality, SAMHSA. Substate estimates of substance use and mental illness from the 2012, 2013 and 2014 NSDUH: results and detailed tables. 2015. https://www.samhsa.gov/samhsa-data-outcomes-quality/major-data-collect-ions/ state-reports-NSDUH/2012-2014-substate-reports. Accessed 19 Oct 2018.

7. Center for Behavioral Health Statistics and Quality, SAMHSA. National Survey on Drug Use and Health, 2012, 2013, and 2014. 2015. https://www.samhsa.gov/data/sites/default/files/ NSDUHsubstateAgeGroupTabs2014/NSDUHsubstateAgeGroupTabs2014.pdf. Accessed 19 Oct 2018.

8. Jamal A, Homa DM, O'Connor E, Babb SD, Caraballo RS, Singh T, et al. Current cigarette smoking among adults-United States, 2005-2014. MMWR Morb Mortal Wkly Rep. 2015;64(44):1233-40. https://www.cdc.gov/mmwr/pdf/wk/mm6444.pdf. Accessed 18 Oct 2018.

9. Pew Research Center. Mobile fact sheet. Pew Research Internet \& Technology Project. 2018. http://www.pewinternet.org/fact-sheet/mobile/. Accessed 18 Oct 2018.

10. Pew Research Center. Social media fact sheet. Pew Research Internet $\&$ Technology Project. 2018. http://www.pewinternet.org/fact-sheet/social-media/. Accessed 18 Oct 2018.

11. Nielsen. 2016 Nielsen social media report. 2017. https://www.nielsen.com/us/en/insights/ reports/2017/2016-nielsen-social-media-report.html. Accessed 19 Oct 2018.

12. Centers for Disease Control and Prevention-CDC. 2014. Building our understanding: culture insights communicating with Hispanic/Latinos. Creating a Culture of Healthy Living. 2014. https://www.cdc.gov/nccdphp/dch/programs/healthycommunitiesprogram/tools/. Accessed 19 Oct 2018.

13. Free C, Knight R, Robertson S, Whittaker R, Edwards P, Zhou W, et al. Smoking cessation support delivered via mobile phone text messaging (txt2stop): a single-blind, randomized trial. Lancet. 2011;378:49-55.

14. Ramo DE, Rodriguez TM, Chavez K, Sommer MJ, Prochaska JJ. Facebook recruitment of young adult smokers for a cessation trial: methods, metrics, and lessons learned. Internet Interv. 2014;1:58-64. https://doi.org/10.1016/j.invent.2014.05.001.

15. Ramo DE, Liu H, Prochaska JJ. A mixed-methods study of young adults' receptivity to using Facebook for smoking cessation: if you build it, will they come? Am J Health Promot. 2015;29:e126-35. https://doi.org/10.4278/ajhp.130326-QUAL-128.

16. Partridge SR, McGeechan K, Hebden L, Balestracci K, Wong AT, Denney-Wilson E, et al. Effectiveness of a mHealth lifestyle program with telephone support (TXT2BFiT) to prevent unhealthy weight gain in young adults: randomized controlled trial. JMIR Mhealth Uhealth. 2015;3:e66. https://doi.org/10.2196/mhealth.4530.

17. Kerr DA, Harray AJ, Pollard CM, Dhaliwal SS, Delp EJ, Howat PA, et al. The connecting health and technology study: a 6-month randomized controlled trial to improve nutrition behaviours using a mobile food record and text messaging support in young adults. Int J Behav Nutr Phys Act. 2016;13:52. https://doi.org/10.1186/s12966-016-0376-8. 
18. Stephens J, Allen J. Mobile phone interventions to increase physical activity and reduce weight: a systematic review. J Cardiovasc Nurs. 2013;28(4):320-9. https://doi.org/10.1097/ JCN.0b013e318250a3e7.

19. McAlister AL, Rabius V, Geiger A, Glynn TJ, Huang P, Todd R. Telephone assistance for smoking cessation: one year cost effectiveness estimations. Tob Control. 2004;13:85-6. https://doi.org/10.1136/tc.2003.004515.

20. Rabius V, McAlister AL, Geiger A, Huang P, Todd R. Telephone counseling increases cessation rates among young adult smokers. Health Psychol. 2004;23(5):539-41. https://doi. org/10.1037/0278-6133.23.5.539.

21. Rabius V, Pike KJ, Hunter J, Wiatrek D, McAlister AL. Effect of frequency and duration in telephone counseling for smoking cessation. Tob Control. 2007;16(Suppl 1):i71-4.

22. Stead LF, Perera R, Lancaster T. A systematic review of interventions for smokers who contact quitlines. Tob Control. 2007;16(Suppl 1):i3-8.

23. Stead LF, Lancaster T, Perera R. Telephone counseling for smoking cessation. Cochrane Database Syst Rev. 2006. https://doi.org/10.1002/14651858.CD002850.pub2

24. Bailey LA. Quitlines today and in the future. Texas Tobacco Summit presentation. North American Quitline Consortium. 2014. http://c.ymcdn.com/sites/www.naquitline.org/resource/resmgr/research/june262014baileyquitlinepres.pdf. Accessed 18 Oct 2018.

25. Tindle HA, Daigh R, Reddy VK, Bailey LA, Ochs JA, Maness MH, et al. eReferral between hospitals and quitlines. Am J Prev Med. 2006;51(4):522-6. https://doi.org/10.1016/j. amepre.2016.05.024.

26. Whittaker R, McRobbie H, Bullen C, Rodgers A, Gu Y. Mobile phone-based interventions for smoking cessation. Cochrane Database Syst Rev. 2016;4:CD006611. https://doi. org/10.1002/14651858.CD006611.pub4.

27. Free C, Whittaker R, Knight R, Abramsky T, Rodgers A, Roberts IG. Txt2stop: a pilot randomized controlled trial of mobile phone-based smoking cessation support. Tob Control. 2009;18(2):88-91. https://doi.org/10.1136/tc.2008.026146.

28. Rodgers A, Corbett T, Bramley D, Riddell T, Wills M, Lin RB, et al. Do u smoke after txt? Results of a randomized trial of smoking cessation using mobile phone text messaging. Tob Control. 2005;14(4):255-61.

29. Whittaker R, Dorey E, Bramley D, Bullen C, Denny S, Elley CR, et al. A theory-based video messaging mobile phone intervention for smoking cessation: randomized controlled trial. J Med Internet Res. 2011;13(1):e10. https://doi.org/10.2196/jmir.1553.

30. Bock BC, Heron KE, Jennings EG, Magee JC, Morrow KM. User preferences for a text message-based smoking cessation intervention. Health Educ Behav. 2013;40(2):152-9. https://doi.org/10.1177/1090198112463020.

31. Graham AL, Fang Y, Moreno JL, Streiff SL, Villegas J, Muñoz RF, et al. Online advertising to reach and recruit Latino smokers to an internet cessation program: impact and costs. J Med Internet Res. 2012;14(4):e116. https://doi.org/10.2196/jmir.2162.

32. Texas Demographic Center. Texas population estimates by age, sex, and race/ethnicity for state and counties-2015. 2015. http://txsdc.utsa.edu/Data/TPEPP/Estimates/. Accessed 19 Oct 2018 .

33. U.S. Census Bureau. American Fact Finder, 2006-2010 American Community Survey: age by language spoken at home, Hispanic or Latino. 2015. http://factfinder2.census.gov. Accessed 19 Oct 2018 .

34. Velicer WF, Prochaska JO. A comparison of four self-report smoking cessation outcome measures. Addict Behav. 2004;29(1):51-60. https://doi.org/10.1016/S0306-4603(03)00084-4.

35. Benowitz NL, Jacob IIIP, Ahijevych K, Jarvis MJ, Hall S, LeHouezec J, et al. Biochemical verification of tobacco use and cessation. Nicotine Tob Res. 2002;4(2):149-59. 
Open Access This chapter is licensed under the terms of the Creative Commons AttributionNonCommercial 4.0 International License (http://creativecommons.org/licenses/by-nc/4.0/), which permits any noncommercial use, sharing, adaptation, distribution and reproduction in any medium or format, as long as you give appropriate credit to the original author(s) and the source, provide a link to the Creative Commons license and indicate if changes were made.

The images or other third party material in this chapter are included in the chapter's Creative Commons license, unless indicated otherwise in a credit line to the material. If material is not included in the chapter's Creative Commons license and your intended use is not permitted by statutory regulation or exceeds the permitted use, you will need to obtain permission directly from the copyright holder. 